\title{
The Relationship between Autonomy and Quality of Health Care among Staff Nurses
}

\author{
Zainab A. Alshaikh ${ }^{1}$, Manal M. Bakr ${ }^{2}$ and Sohair M. Allam ${ }^{3}$ \\ ${ }^{1}$ B.SC in nursing sciences, ${ }^{2}$ Assistant professor of Nursing Administration, ${ }^{3}$ Assistant \\ professor of Nursing Administration, Faculty of Nursing, Menoufia University
}

\begin{abstract}
Background: Autonomy is the main element of professional nursing practice, which leads to improve patient outcomes. Nurses who have a higher degree of autonomy in their practice provide high-quality patient care. Purpose of the study: Assess the relationship between autonomy and quality of health care among staff nurses. Design: A descriptive correlational research design was utilized for this study. Setting: Conducted at selected general departments and closed units of Teaching Hospital. Subjects: Convenience sample of 250 staff nurses and 100 patients were included at this study. Instruments: Two instruments were used for data collection: instrument I: Dempster Practice Behaviors Scale and instrument II:Patient's Quality of Health Care Questionnaire. Results: Revealed that the majority of studied nurses had moderate autonomy level (71.6\%) In addition, nearly two thirds of studied patients had moderate health care quality (65\%) Conclusion: There was a positive non-significant correlation between nurses' perception of autonomy and patients' perception of quality of health care. Recommendation: Encourage nurses to participate in decision-makings to create mutual trust between managers and super visors and staff, and provide continuous in service education to increase nurses' knowledge base.
\end{abstract}

Key Words: Autonomy, Quality of healthcare, and Staff nurses.

\section{Introduction}

Autonomy is abstract and complex concept, with which individuals gain the capacity to make an informed and independent decision in order to achieve the desired outcome. Some scholars have even considered autonomy as an individual right. Autonomy is a core ethical principle in the field of healthcare. Nursing professional autonomy is a complex, multi-dimensional concept and the basis of professionalism. It is considered a professional right to be able to function autonomously within the pre-defined framework of duties and working conditions. However, professional autonomy does not contradict with full collaboration 
within healthcare settings, which are often complex and in which teamwork is a prerequisite (Rouhi-Balasi et al., 2020) (Barnes., 2015).

Moreover, professional autonomy includes the right to independent decision-making and to have control over the core nursing activities. Additional indicators of professional autonomy are critical thinking, clinical decision-making, freedom of action, and self-governance. The extent of autonomy among nurses is associated with their level of knowledge and education as well as life experiences, credence, and sociability (Varjus, 2011 \& Hirani \& Olson., 2016)

Clinical autonomy is evident where nurses have the authority to exercise their capacity for clinical judgment in the realm of clinical nursing care and collaboratively with other professions in overall patient care while practicing within a professional nursing context. Clinical autonomy relies on nurses' clinical knowledge and judgment and serves to benefit patients directly, while job autonomy and control over nursing practices rely on nurses' organizational knowledge and influence (Rao et al., 2018). In clinical setting, autonomy means acting independently without being restricted by bureaucratic rules of hospitals and receiving orders from others (Cotter, 2016).

For administration, quality means providing the best human and material elements necessary to provide the service, performing continuous evaluation of services provided by doctors and other service providers, and training human resources to ensure the continuous improvement of these services. As for the patients, quality means treating her/ him with full respect, attention, sympathy and understanding from all human elements dealing directly or indirectly with her/him during his stay in the hospital. Whereas, for doctors, quality means providing the highest level of knowledge, skills, and medical equipment and devices to take care of patients (Birdogan \& Iskender, 2015).

Quality in healthcare is a production of cooperation between the patient and the healthcare provider in a supportive environment. Healthcare service quality depends on personal factors of the healthcare service provider and the patient and factors pertaining to the healthcare organization and broader 
environment. Differences in internal and external factors such as availability of resources and collaboration and cooperation among providers affect the quality of care and patient outcomes (Mosadeghrad, 2013)

\section{Significant of the Study}

International studies provide evidence that when nurses do not have the ability to exercise their clinical and organizational knowledge, patient is put at risk. In Egypt many health care organizations have not focused sufficiently on nurses' autonomy. Consequently, nurses' autonomy became one of the most prevalent issues that needed in our health care organizations. Autonomy help nurses to feel a greater responsibility for the outcomes, increases work motivation, and quality of health care. From clinical experience the investigator observed that the nurses in the intensive care unit who care the patient on a ventilator, and connected with endotracheal tube, suddenly the tube dislocated and shifted from the trachea into the esophagus and the patient's condition has deteriorated because the assigned nurse may not has professional autonomy to manage the situation. Also some nurses suffered from centralized nursing scheduling and they don't have the ability to use self-scheduling perhaps they have lack of autonomy. For these reasons, the current study will be conducted to determine the relationship between autonomy and patients' quality of health care among staff nurses at Shebin El-Kom Teaching Hospital.

\section{Purpose of the Study}

The current study aimed to assess the relationship between autonomy, and quality of health care among staff nurses at Shebin El-Kom Teaching Hospital.

\section{Research questions}

1) What are the levels of autonomy among staff nurses at Shebin Elkom Teaching Hospital?

2) What are the levels of quality of health care among patients at Shebin El-kom Teaching Hospital?

3) What is the relation between perceived level of nurses' autonomy and level of quality of patient's health care?

\section{Methods}

\section{Research design:-}

A descriptive correlational research design was used for conducting this study. 


\section{Settings:-}

The study was conducted at selected general departments and closed units of Shebin El-Kom Teaching Hospital.

\section{Sample:-}

The subjects included in the present study consisted of two groups

- Group 1: Convenience sample of 250 staff nurses were selected to constitute the present study sample from Teaching Hospital.

- Group 2: Convenience sample of 100 patients were selected to constitute the present study sample from Teaching Hospital.

\section{Instruments}

Instrument I: Dempster Practice Behaviors Scale (DPBS):

It was developed by Dempster (1990). It developed to assess autonomy level among staff nurses at teaching hospitals. It consisted of two parts:

- The first part: Included personal characteristics of study sample such as: age, gender, unit, educational level, and years of experience.

- The second part: The Dempster Practice Behaviors Scale (DPBS) it, consisted of 30 items to assess the level of autonomy among staff nurses.

The scoring system of instrument one the frequency of responses to each subscale assessed by using a five point likert scale from not at all true to extremely true. The total score allocated to each item as follows: not at all true (1), slightly true (2), moderately true (3), very true (4), and extremely true (5). The total score of subject response is 150 . The score was graded as follows:

Table 1: Scoring system of Autonomy Questionnaire:

\begin{tabular}{|l|l|}
\hline $\begin{array}{l}\text { The level of } \\
\text { autonomy }\end{array}$ & \multicolumn{1}{|c|}{ The total score (150) } \\
\hline $\begin{array}{l}\text { Low level of } \\
\text { autonomy. }\end{array}$ & $\begin{array}{l}\text { if the score }(30-\leq 75) \text { of } \\
\text { total autonomy score }\end{array}$ \\
\hline $\begin{array}{l}\text { Moderate level } \\
\text { of autonomy. }\end{array}$ & $\begin{array}{l}\text { if the score }(76-\leq 112) \text { of } \\
\text { total autonomy score }\end{array}$ \\
\hline $\begin{array}{l}\text { High level of } \\
\text { autonomy. }\end{array}$ & $\begin{array}{l}\text { if the score }(113-\leq 150) \text { of } \\
\text { the total autonomy score }\end{array}$ \\
\hline
\end{tabular}

Instrument II: Patient's Quality of Health Care Questionnaire (PQHCQ): It was developed by Laschinger et al (2005) and European patient forum (2017) and adopted by the investigator. It developed to assess patient quality of health care at 
Teaching Hospital. It consisted of two parts:

- The first part: Included personal characteristics of study sample such as: age, gender, unit and educational level.

- The second part: The Patient's Quality of Health Care Questionnaire (PQHCQ) it, consisted of 29 items to assess the level of quality of health care among Patients.

The scoring system of instrument two the frequency of responses to each subscale assessed by using a five point likert scale from poor to excellent. The total score allocated to each item as follows: excellent (5), very good (4), good (3), fair (2), and poor (1). The total score of subject response is 145 . The score was graded as follows:

Table 2: Scoring system of Quality

Questionnaire:

\begin{tabular}{|l|c|}
\hline $\begin{array}{l}\text { The level of } \\
\text { quality }\end{array}$ & The total score (145) \\
\hline $\begin{array}{l}\text { Low level of } \\
\text { quality. }\end{array}$ & $\begin{array}{c}\text { if the score ( } \leq 72) \text { of } \\
\text { total quality score }\end{array}$ \\
\hline $\begin{array}{l}\text { Moderate level of } \\
\text { quality. }\end{array}$ & $\begin{array}{c}\text { if the score (73 - } \leq 108) \\
\text { of total quality score }\end{array}$ \\
\hline $\begin{array}{l}\text { High level of } \\
\text { quality. }\end{array}$ & $\begin{array}{l}\text { if the score (109- } \leq 145) \\
\text { of the total quality score }\end{array}$ \\
\hline
\end{tabular}

Validity of the study instruments:-

The instrument were distributed to a Panel of Experts consisted of five Assistant Professors in the field of Nursing Administration to judge the content and Face Validity of the instruments, presented from different Faculties of Nursing affiliated to Menoufia , Tanta and Ain-Shams Universities.

\section{Field work}

Before beginning to collect data from the study sample the investigator introduced herself to them, explained the aim of the study, and informed them that their information will be treated confidential and will be used only for the purpose of the research; additionally, each participant was notified about the right to accept or refuse to participate in the study. Data was collected in the morning and afternoon shifts and the subjects' response to questions in presence of the investigator to ascertain that all questions were answered. The time required for each nurse to fill the questionnaire was estimated to be 30 35 minutes. The data collection started in August 2020 and ended in December 2020. The average number of nurses who filled the tools were 12 per day. 


\section{Ethical considerations}

Before beginning to collect data from the study subjects, a written (official) approval letter was submitted from the dean of the nursing college to the director of Shebin El-Kom Teaching Hospital to get his permission to carry out the study. The study was conducted with careful attention to ethical standards of research and rights of the participants. The sample rights were protected by ensuring voluntary participation; so that an informed consent was obtained by explaining the purpose, nature, time of conducting the study, potential benefits of the study and how data will be collected. The investigator informed them that their information will be treated confidential and will be used only for the purpose of the research, additionally, each participant was notified about the right to accept or refuse to participate in the study.

\section{Statistical analysis}

Data was entered and analyzed by using SPSS (Statistical Package for
Social Science) version 22. Graphics were done using Excel program, but correlation figure between total score nursing perception about autonomy and total score of patients perception about quality of health care provided at Shebin El Kom Teaching hospital, was done

through the SPSS program. Quantitative data were presented by mean (X) and standard deviation (SD). It was analyzed using student ttest for comparison between two means, and ANOVA (F) test for comparison between more than two means. Qualitative data were presented in the form of frequency distribution tables, number and percentage. It was analyzed by chisquare $\left(\chi^{2}\right)$ test. However, if an expected value of any cell in the table was less than 5, Fisher Exact test was used( if the table was 4 cells), or Likelihood Ratio (LR) test (if the table was more than 4 cells). Level of significance was set as $\mathrm{P}$ value $<0.05$ for all significant tests.

\section{RESULTS}

Table (3) : Ranking with mean scores of autonomy among studied nurses $(n=250)$ 


\begin{tabular}{|c|c|c|c|c|}
\hline Autonomy items & Minimum & Maximum & Mean & $\pm \mathrm{SD}$ \\
\hline Take responsibility and am accountable for my actions. & 1.0 & 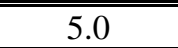 & 4.0 & \pm 0.9 \\
\hline $\begin{array}{l}\text { Have developed the image of myself as an independent } \\
\text { professional. }\end{array}$ & 1.0 & 5.0 & 3.4 & \pm 1.0 \\
\hline Base my actions on the full scope of my knowledge and ability. & 1.0 & 5.0 & 3.5 & \pm 0.8 \\
\hline Self-determine my role and activities. & 1.0 & 5.0 & 3.2 & \pm 0.9 \\
\hline Derive satisfaction from what I do. & 1.0 & 5.0 & 4.0 & \pm 0.8 \\
\hline Take control over my environment and situations I confront. & 1.0 & 5.0 & 3.9 & \pm 0.9 \\
\hline Am valued for my independent actions. & 1.0 & 5.0 & 4.0 & \pm 0.9 \\
\hline Am constrained by bureaucratic limitations. & 1.0 & 5.0 & 2.5 & \pm 1.1 \\
\hline Provide quality services through my actions. & 2.0 & 5.0 & 4.3 & \pm 0.7 \\
\hline Am confident in my abilities to perform my role independently. & 1.0 & 5.0 & 3.8 & \pm 0.9 \\
\hline Have been professionally socialized to take independent action. & 1.0 & 5.0 & 3.6 & \pm 0.9 \\
\hline Function with the authority to do what I know should be done. & 1.0 & 5.0 & 2.9 & \pm 1.1 \\
\hline Have too many routine tasks to exercise independent action. & 1.0 & 5.0 & 3.6 & \pm 0.9 \\
\hline Have a sense of professionalism. & 1.0 & 5.0 & 4.3 & \pm 0.9 \\
\hline Have the rights and privileges I deserve. & 1.0 & 5.0 & 3.7 & \pm 1.1 \\
\hline Have the professional experience needed for independent action. & 1.0 & 5.0 & 3.7 & \pm 0.9 \\
\hline Am restrained in what I can do because I am powerless. & 1.0 & 5.0 & 1.7 & \pm 1.0 \\
\hline $\begin{array}{l}\text { Collaborate with others outside my field when I feel there is a } \\
\text { need. }\end{array}$ & 1.0 & 5.0 & 4.1 & \pm 0.9 \\
\hline Derive feelings of self-respect and esteem from what I do. & 1.0 & 5.0 & 4.3 & \pm 0.8 \\
\hline Make my own decisions related to what I do. & 2.0 & 5.0 & 3.5 & \pm 0.8 \\
\hline Possess ownership of my practice; that is, my role belongs to me. & 2.0 & 5.0 & 3.9 & \pm 0.9 \\
\hline Have the power to influence decisions and actions of others. & 1.0 & 5.0 & 3.3 & \pm 1.2 \\
\hline Have a sense of self-achievement. & 2.0 & 5.0 & 4.3 & \pm 0.8 \\
\hline Am provided with a legal basis for independent functioning. & 1.0 & 5.0 & 3.7 & \pm 1.0 \\
\hline Demonstrate mastery of skills essential for freedom of action. & 2.0 & 5.0 & 4.1 & \pm 0.7 \\
\hline I always advocate patients' rights. & 1.0 & 5.0 & 1.6 & \pm 1.0 \\
\hline Have the respect of those in other disciplines. & 1.0 & 5.0 & 4.0 & \pm 0.8 \\
\hline Cannot optimally function because I do not have legal status. & 1.0 & 5.0 & 1.5 & \pm 1.0 \\
\hline Establish the parameters and limits of my practice activities. & 1.0 & 5.0 & 3.6 & \pm 0.8 \\
\hline Accept the consequences for the choices I make. & 1.0 & 5.0 & 3.8 & \pm 0.9 \\
\hline Mean total score of perceived autonomy & 62 & 138 & 105.8 & \pm 12.5 \\
\hline
\end{tabular}

Table (3) Illustrates that the ranking with mean scores of autonomy among studied nurses $(n=250)$. From the table, it was observed that:

The highest mean scores were 4.3 for four items " Provide quality services through my actions."," Have a sense of professionalism.", " Derive feelings of self-respect and esteem from what I do.", and " Have a sense of selfachievement" . While the lowest mean score was 1.5 for "Cannot optimally function because I do not have legal status." and 1.7 for "Am restrained in what I can do because I am powerless". The mean total score of nursing perceived autonomy was $105.8 \pm 12.5$ with a range of $62-138$.

Table (4): Distribution of the studied nurses according to their personal characteristics $(n=250)$ 


\begin{tabular}{|l|c|c|}
\hline \multicolumn{1}{|c|}{ personal characteristics } & No. & $\%$ \\
\hline \hline Age (Years) : & & \\
- 18 - <35 Years & 142 & 56.8 \\
- $35-<45 \mathrm{Y}$ & 66 & 26.4 \\
- $45-60 \mathrm{Y}$ & 42 & 16.8 \\
\hline \hline Gender : & & \\
- Male & 62 & 24.8 \\
- female & 188 & 75.2 \\
\hline \hline Participants unites: & & \\
- General departments & 109 & 43.6 \\
- Critical care Unites & 141 & 56.4 \\
\hline \hline Education: & & \\
- Nursing diploma degree & 113 & 45.2 \\
- Associated degree & 29 & 11.6 \\
- Bachelor degree & 108 & 43.2 \\
\hline \hline Experience : & & \\
- $-<10$ Y & 118 & 47.2 \\
- 10 - < 20 Y & 84 & 33.6 \\
- $\geq 20 \mathrm{Y}$ & 48 & 19.2 \\
\hline \hline Total & $\mathbf{2 5 0}$ & $\mathbf{1 0 0}$ \\
\hline
\end{tabular}

Table (4) illustrates that distribution of studied staff nurses regarding to their personal characteristics. From the table, it was observed that: More than half of the studied nurses aged between $18-<35$ Y (56.8\%), approximately one quarter of them were male nurses $(24.8 \%)$, and approximately two thirds of them were working at Critical care units $(56.4 \%)$ Concerning experience, approximately one half of them had an experience of $1-<10$ years (47.2\%), and more than one third of them had experience of $10-<20$ years (33.6\%). Majority of them had a Nursing diploma degree $(45.2 \%)$.

Fig.1: Percent distribution of age of studied nurses $(\mathrm{N}=250)$

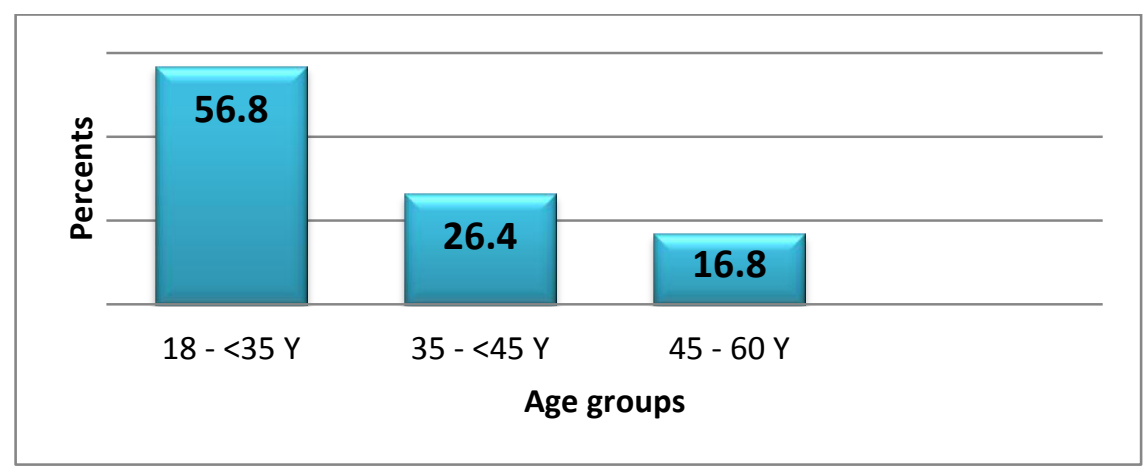

Figure (1) illustrates that percent distribution of age of studied nurses. From the figure, it was observed that: More than half of the studied nurses aged between 18
- < 35 Y (56.8\%), while more than one quarter of the studied nurses aged between $35-<45$ Y (26.4\%), and while less than one fifth of the studied nurses aged between 45 - 60 YS (16.8\%). 
Table (5): Ranking with mean scores of quality of health care among studied patients $(n=100)$

\begin{tabular}{|c|c|c|c|c|}
\hline Quality of health care & Minimum & Maximum & Mean & \pm SD \\
\hline $\begin{array}{l}\text { Attitudes of healthcare workers towards patients are positive (e.g., } \\
\text { respect, empathy). }\end{array}$ & 1.0 & 5.0 & 3.6 & \pm 1.2 \\
\hline Communication skills of healthcare workers are good. & 1.0 & 5.0 & 3.5 & \pm 1.0 \\
\hline Diagnostic procedures are accurate. & 1.0 & 5.0 & 3.6 & \pm 1.0 \\
\hline There is public investment of resources and funds in healthcare. & 1.0 & 5.0 & 2.5 & \pm 1.1 \\
\hline All the latest treatments are available to patients. & 1.0 & 5.0 & 3.2 & \pm 0.9 \\
\hline Diagnosis, treatment and follow-up is timely (quickly). & 1.0 & 5.0 & 3.4 & \pm 0.9 \\
\hline Treatment is clinically effective. & 1.0 & 5.0 & 3.5 & \pm 1.0 \\
\hline Cost of the services for patients is affordable. & 1.0 & 5.0 & 2.8 & \pm 1.2 \\
\hline Patient participates in shared decision-making. & 1.0 & 5.0 & 2.7 & \pm 1.0 \\
\hline Healthcare environment is aesthetically nice. & 1.0 & 5.0 & 3.4 & \pm 1.1 \\
\hline Care/treatment is safe. & 1.0 & 5.0 & 3.5 & \pm 1.0 \\
\hline $\begin{array}{l}\text { Information you were given, the nurses explain the tests and } \\
\text { treatments clearly and completely, and what to expect. }\end{array}$ & 1.0 & 5.0 & 2.9 & \pm 1.0 \\
\hline $\begin{array}{l}\text { Instructions, nurses explained how to prepare for tests and } \\
\text { operations. }\end{array}$ & 1.0 & 5.0 & 3.3 & \pm 0.9 \\
\hline $\begin{array}{l}\text { Ease of getting information, readiness of nurses to answer the } \\
\text { patient questions. }\end{array}$ & 1.0 & 5.0 & 3.0 & \pm 1.0 \\
\hline $\begin{array}{l}\text { Information given by nurses, nurses communicated with patients, } \\
\text { families, and doctors. }\end{array}$ & 1.0 & 5.0 & 3.3 & \pm 1.0 \\
\hline $\begin{array}{l}\text { Informing family or friends, nurses keep the patient informed with } \\
\text { his condition and needs. }\end{array}$ & 1.0 & 5.0 & 3.0 & \pm 1.0 \\
\hline $\begin{array}{l}\text { Attention of nurses to your condition, how often nurses checked } \\
\text { on you and how well they kept track of how you were doing. }\end{array}$ & 1.0 & 5.0 & 3.1 & \pm 0.9 \\
\hline $\begin{array}{l}\text { Consideration of your needs, willingness of the nurses to be } \\
\text { flexible in meeting the patient needs and preferences. }\end{array}$ & 1.0 & 4.0 & 3.1 & \pm 0.9 \\
\hline $\begin{array}{l}\text { The daily routine of the nurses, how well they adjusted their } \\
\text { schedules to your needs. }\end{array}$ & 1.0 & 5.0 & 3.1 & \pm 0.9 \\
\hline $\begin{array}{l}\text { Helpfulness, the ability of the nurses to make you comfortable and } \\
\text { reassure you. }\end{array}$ & 1.0 & 5.0 & 3.7 & \pm 1.0 \\
\hline Nursing staff response to your calls, how quick they were to help. & 1.0 & 5.0 & 3.3 & \pm 0.9 \\
\hline $\begin{array}{l}\text { Skill and competence of nurses, how well things were done, like } \\
\text { giving medicine and handling IVs. }\end{array}$ & 1.0 & 5.0 & 4.1 & \pm 1.0 \\
\hline $\begin{array}{l}\text { Restful atmosphere provided by nurses, amount of peace and } \\
\text { quiet. }\end{array}$ & 1.0 & 5.0 & 3.7 & \pm 1.1 \\
\hline Privacy, provisions for your privacy by nurses. & 1.0 & 5.0 & 3.4 & \pm 1.1 \\
\hline $\begin{array}{l}\text { Discharge instructions, how clearly and completely the nurses told } \\
\text { you what to do and what to expect when you left the hospital. }\end{array}$ & 1.0 & 5.0 & 3.1 & \pm 1.1 \\
\hline $\begin{array}{l}\text { Coordination of care after discharge, nurses' efforts to provide for } \\
\text { your needs after you left the hospital. }\end{array}$ & 1.0 & 5.0 & 1.7 & \pm 1.1 \\
\hline $\begin{array}{l}\text { Overall quality of care and services you received during your } \\
\text { hospital stay. }\end{array}$ & 1.0 & 5.0 & 3.2 & \pm 1.0 \\
\hline $\begin{array}{l}\text { Overall quality of nursing care you received during your hospital } \\
\text { stay. }\end{array}$ & 1.0 & 5.0 & 3.2 & \pm 1.0 \\
\hline In general, would you say your health is. & 1.0 & 5.0 & 3.5 & \pm 1.0 \\
\hline Mean total score of quality of health care & 38 & 132 & 93.3 & \pm 18.3 \\
\hline
\end{tabular}


Table (5) Illustrates that descriptive statistics of the studied patients' perception about quality of health care. From the table, it was observed that: The highest mean score was 4.1 for the item "Skill and competence of nurses, how well things were done, like giving medicine and handling IVs". While the lowest mean score was 1.7 for "Coordination of care after discharge, nurses' efforts to provide for your needs after you left the hospital ". The mean total score of studied patients' perception about health care was $93.3 \pm 18.3$ with a range of $38-132$.

Fig.2: percent distribution of autonomy groups $(n=250)$

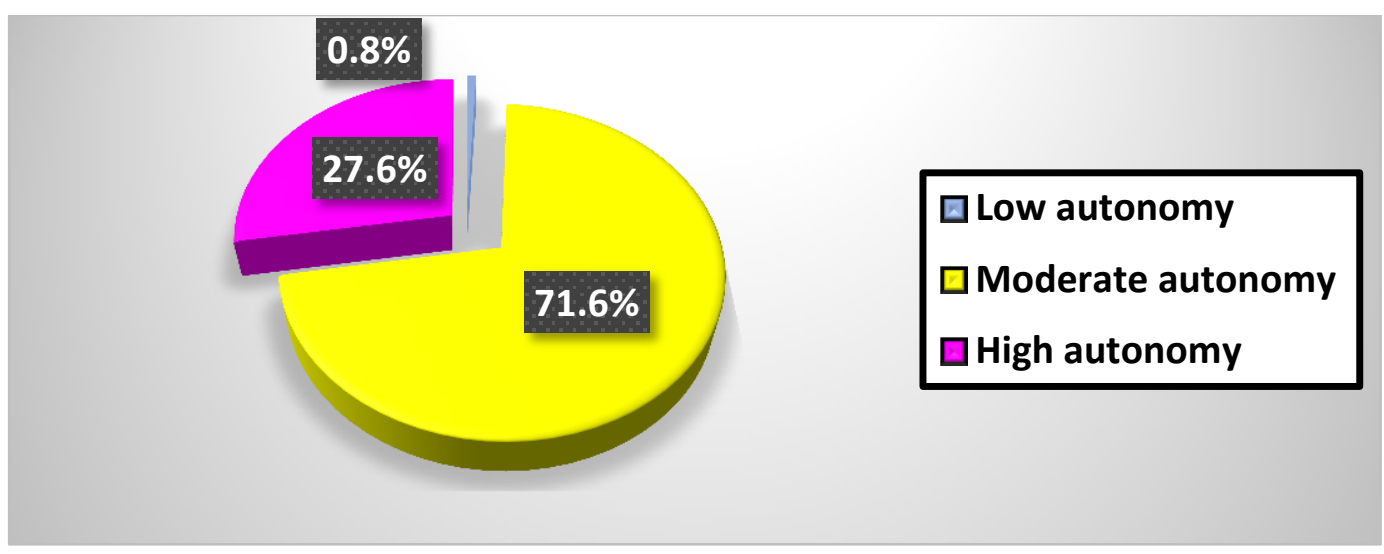

Figure (2) illustrates that percent one third of the studied nurses showed distribution of autonomy groups. From the figure, it was observed that: The majority of the studied nurses showed moderate high autonomy (27.6\%), and while the lowest percentage was the low autonomy with $0.8 \%$. autonomy level (71.6\%), approximately

Table 6: Correlation coefficient between nurses autonomy and patients' quality of care $(\mathrm{N}=100)$

\begin{tabular}{|c||c|c|}
\hline \multirow{2}{*}{$\mid$} & \multicolumn{2}{c|}{ Quality of care } \\
\hline \hline \multirow{2}{*}{ Autonomy } & $\mathrm{r}$ & $\mathrm{P}$ \\
\cline { 2 - 3 } & 0.038 & 0.71 \\
\hline
\end{tabular}

Table (6) illustrates that Correlation coefficient between nurses' autonomy and patients' quality of care. From the table, it was observed that: Correlation coefficient between total score of nurses 'perception about autonomy as independent variable, and total score of patients' perceived quality of health care at Shebin-El Kom Teaching Hospital as dependent variable with regression line. There was a weak positive correlation between total score of nurses 'perception autonomy as independent variable, and total score of patients' perceived quality of health care at Shebin-El Kom Teaching Hospital $(\mathrm{r}=0.038, \mathrm{p}=0.71)$. 


\section{Discussion}

Among the members of the healthcare team, nurses have a significant role in care provision; thus, the quality of care depends, to a large extent, on their service provision. Moreover, professionalism and professional behavior in the medical sciences is very important today. Therefore, it is essential that the nursing profession adapts to these changes and continually updates itself. Hence, the nurse is expected to become a person who thinks, makes decisions, and takes responsibility for his/her decisions, not just someone who takes orders (Tabatabai A, Abbaszadeh A, Mohammadnejhad E., 2015).

The most basic way for nurses to fulfill this expectation is to have individual and professional autonomy (Rao AD, Kumar A, McHugh M., 2017). Autonomy is defined as the ability to apply professional knowledge to patient care and clinical decision-making. Thus, a comprehensive explanation of the concept of professional autonomy in nursing seems necessary due to the important role of autonomy in improving the quality of patient care through timely decision-making at the patient's bedside, as well as reducing stress, and increasing job satisfaction, and attracting and retaining nurses ( Sarkoohijabalbarezi Z, Ghodousi A, Davaridolatabadi E., 2017).

This current study was conducted to assess the relationship between autonomy and quality of health care among staff nurses through answering the following questions; the $1^{\text {st }}$ question was "What are the levels of autonomy among staff nurses at Shebin El-kom Teaching Hospital? ", the $2^{\text {nd }}$ question was "What are the levels of quality of health care among patients at Shebin El-kom Teaching Hospital?", and finally the $3^{\text {rd }}$ question was "What is the relation between perceived level of nurses autonomy and level of quality of patient's health care? ".

The current study showed that the majority of studied nurses had moderate autonomy level, while a very small percentage of studied nurses had low autonomy. From the investigator's point of view, this may be due to; the nurses are working at a governmental hospital which have a lack of organizational support and the managers don't let them participate in decision making process, lack of nurse's knowledge and the limited 
responsibility afforded to them, also the doctor is seen, especially in the hospital environment, as the only professional responsible for all patient care and decisions, and lack of appreciation of the profession and respect for the doctors about their knowledge and skills. This finding was consistent with Labrague et al (2018) who conducted a study on "Perceptions of organizational support and its impact on nurses' job outcomes" revealed that the nurses had moderate levels of autonomy.

Also this result was congruent with Paganini \& Bousso (2015) who conducted a study on "Nurses' autonomy in end-of-life situations in intensive care units" revealed that the nurses had a moderate level of autonomy in intensive care units. Also this result was congruent with Finn (2015) who conducted a study on "Autonomy: An important component of nurses' job satisfaction" revealed that the majority of nurses had a moderate level of autonomy. Additionally, this result was congruent with Enns (2013) who conducted a study on "Professional autonomy and work setting as contributing factors to depression and absenteeism in Canadian nurses" revealed that the majority of nurses had a moderate level of autonomy. Also Iranmanesh et al (2014) who conducted a study on 'Nurses' professional autonomy and attitudes toward caring for dying patients in South-East Iran " revealed that the majority of nurses had moderate levels of autonomy.

This finding was incongruent with El Adly (2014) who conducted a study on "The influence of organizational climate on nurses' autonomy" revealed that the nurses had a high autonomy level dealing with patient complaints. Also this result was incongruent with Laschinger, Finegan, Shamian \& Wilk (2011) who conducted a study on "Impact of structural and psychological empowerment on job autonomy in nursing work settings" revealed that more than half of nurses perceived a high autonomy level. Additionally, Baykara, \& Sahinoglu (2014) who conducted a study on "An evaluation of nurses' professional autonomy in Turkey " revealed that the most nurses had low level of autonomy. Also, Sarkoohijabalbarezi, Ghodousi, \& Davaridolatabadi (2017) who conducted a study on "The relationship between professional autonomy and moral distress among nurses working in children's units and pediatric 
intensive care wards" revealed that low levels of autonomy among nurses.

Additionally the current study showed that the highest mean scores were four items " Provide quality services through my actions."," Have a sense of professionalism.", " Derive feelings of self-respect and esteem from what I do.", and " Have a sense of selfachievement" . While the lowest mean scores were two items "Cannot optimally function because I do not have legal status.", and "I always advocate patients' rights.", and the mean total score of nursing perceived autonomy was $105.8 \pm 12.5$ with a range of $62-138$. From the investigator's point of view, this may be due to; nurses had an adequate knowledge of their duties, they were responsible and accountable for their actions, they had a clear job description, and they had ability to deal with situation with appropriate action, which considering one of the important tasks of the nurse, and they were supported to develop professionalism consequently autonomy and selfconfidence was increased

\section{Conclusion}

In the light of the current study findings, it was concluded that: the majority of studied nurses had moderate autonomy level. Additionally, the first ranking with the highest mean score of autonomy was related to four items " Provide quality services through my actions."," Have a sense of professionalism.", " Derive feelings of self-respect and esteem from what I do.", and " Have a sense of selfachievement", while the last ranking with the lowest mean score was related to "Cannot optimally function because I do not have legal status".

Additionally, the majority of studied patients had moderate health care quality. Also, the first ranking with the highest mean score of health care quality was related to " Skill and competence of nurses, how well things were done, like giving medicine and handling IVs", while last ranking with the lowest mean score was related to " Coordination of care after discharge, nurses' efforts to provide for your needs after you left the hospital ". Finally, there was a positive weak nonsignificant correlation between nurses' perception of autonomy and patients' perception of quality of health care.

\section{Recommendations}

Based on the findings of this study, the following recommendations are proposed:

\section{I- At hospital level:}


1) Hospital administrators should encourage nurses to participate in decision-makings to create mutual trust between managers and supervisors and staff, and provide continuous in service education to increase nurses' knowledge base.

2) Hospital administrators should set plans to enhance nurses' participation in decision making, encourage them to share their aims, targets, visions and goals, unite them with management and stimulate team spirit.

3) This administration should take their nurses' opinions in consideration, attend to their needs and listen to their concerns, treat each one as an individual with unique needs and consider individual differences.

4) Provide regular training and workshops for nurses to improve their knowledge, awareness, and skill about autonomy and quality of health care.

5) Provide an effective compensation program such as bonuses, flexible work hours to increase the commitment and quality of health care.

\section{II-At educational level:}

1) New trends in nursing administration should be presented as an academic subject for under graduated and evaluated annually for renewal and addition

2) Collaboration protocols between the College of Nursing and the hospital to improve autonomy and competency of nurses.

\section{III-At research level:}

Further researches are required to:

1) Replicate this study at different hospitals and settings with different sample size through which results can be generalized.

2) Study strategies and factors that promote autonomy and participation in decision-making which help to improve quality of health care.

3) Further researches are needed in areas of nurses' autonomy, and quality of health care.

4) Conduct studies to assess factors that enhance autonomy and quality of health care.

\section{References}

Barnes H. (2015). Nurse practitioner role transition: A concept analysis. InNursing 
Forum. Jul (Vol. 50, No. 3, pp. 137-146).

Baykara, Z.G. and S. Sahinoglu,(2014).

An evaluation of nurses' professional autonomy in Turkey. Nurs Ethics,. 21(4), 447Y460. doi:101177/0969733013505307

El Adly, A. (2014). The influence of organizational climate on nurses' autonomy, faculty of nursing Ain shams university. Unpublished Master thesis in nursing administration, pp 60.

Enns V, Currie S, Wang J. (2015). Professional autonomy and work setting as contributing factors to depression and absenteeism in Canadian nurses. Nursing outlook. May 1;63(3):269-77.

Finn, C., P. (2015). Autonomy: An important component of nurses' job satisfaction. International Journal of Nursing Studies, 38(3), 349357.

Hirani SA, Olson J. (2016). Concept Analysis of Maternal Autonomy in the Context of Breastfeeding. Journal of nursing scholarship: an official publication of Sigma
Theta Tau International Honor Society of Nursing. May 1;48(3):276-84.

Iranmanesh, S., Razban, F., Nejad, A.T., Ghazanfari, Z. (2014). Nurses' professional autonomy and attitudes toward caring for dying patients in South-East Iran. Int J Palliat Nurs, 20 pp. 294 300.

Labrague, L., J., McEnroePetitte, D. M., Leocadio, M. C., Van Bogaert, P., \&Tsaras, K. (2018). Perceptions of organizational support and its impact on nurses' job outcomes. Nurs Forum, wileyonlinelibrary.com/journa l/nuf;53:339-347. https://doi.org/10.1111/nuf.1 $\underline{2260}$

LaschingerH.K.S., Finegan J.,ShamianJ.\&WilkP.(2011). Impact of Structural and Psychological Empowerment on Job Strain in Nursing Work Settings: Expanding Kanter Model. Journal of Nursing Administration; 31: 260-272.

Mosadeghrad A.

Healthcare service quality: 
Towards a broad definition.

International Journal of

Health Care Quality Assurance; 26(3):203-219.

Paganini MC, Bousso RS. (2015)

Nurses' autonomy in end- of $^{-}$

life situations in intensive care units. Nurs Ethics; 22:803-14.

Rao, A. D., Kumar, A., \& McHugh, M. (2017). Better nurse autonomy decreases the odds of 30-day mortality and failure to rescue. Journal of Nursing Scholarship, 49, 7379.

https://doi.org/10.1111/inu.1 $\underline{2267}$

Rouhi-Balasi L, Elahi N, Ebadi A, Jahani S, Hazrati M. (2020). Professional autonomy of nurses: A qualitative metasynthesis study. Iranian Journal of Nursing and
Midwifery Research.

Jul;25(4):273.

Sarkoohijabalbarezi Z, Ghodousi A, Davaridolatabadi E. .( 2017). The relationship between professional autonomy and moral distress among nurses working in children's units and pediatric intensive care wards. Int $\mathbf{J}$ Nurs Sci;4:117-21.

Tabatabai A, Abbaszadeh A, Mohammadnejhad E.( 2015). Nursing and professionalism: Perception of cardiac care unit nurses. J Qual Res Health Sci;4:86-96.

Varjus, S.L., H. Leino-Kilpi, and $\mathrm{T}$. Suominen.(2011), Professional autonomy of nurses in hospital settings--a review of the literature. Scand J Caring Sci, 2011. 25(1): p. 201-7. 